\title{
Estimating the effective elastic modulus and specific fracture energy of snowpack layers from field experiments
}

\author{
ALEC VAN HERWIJNEN, ${ }^{1}$ JOHAN GAUME, ${ }^{1}$ EDWARD H. BAIR, ${ }^{2}$ BENJAMIN REUTER, ${ }^{1}$ \\ KARL W. BIRKELAND, ${ }^{3}$ JÜRG SCHWEIZER ${ }^{1}$
}

\author{
${ }^{1}$ WSL Institute for Snow and Avalanche Research SLF, Davos, Switzerland \\ ${ }^{2}$ Earth Research Institute, University of California, Santa Barbara, CA, USA \\ ${ }^{3}$ USDA Forest Service National Avalanche Center, Bozeman, MT, USA \\ Correspondence: Alec van Herwijnen <vanherwijnen@slf.ch>
}

\begin{abstract}
Measurements of the mechanical properties of snow are essential for improving our understanding and the prediction of snow failure and hence avalanche release. We performed fracture mechanical experiments in which a crack was initiated by a saw in a weak snow layer underlying cohesive snow slab layers. Using particle tracking velocimetry (PTV), the displacement field of the slab was determined and used to derive the mechanical energy of the system as a function of crack length. By fitting the estimates of mechanical energy to an analytical expression, we determined the slab effective elastic modulus and weak layer specific fracture energy for $\mathbf{8 0}$ different snowpack combinations, including persistent and nonpersistent weak snow layers. The effective elastic modulus of the slab ranged from 0.08 to $34 \mathrm{MPa}$ and increased with mean slab density following a power-law relationship. The weak layer specific fracture energy ranged from 0.08 to $2.7 \mathrm{~J} \mathrm{~m}^{-2}$ and increased with overburden. While the values obtained for the effective elastic modulus of the slab agree with previously published low-frequency laboratory measurements over the entire density range, the values of the weak layer specific fracture energy are in some cases unrealistically high as they exceeded those of ice. We attribute this discrepancy to the fact that our linear elastic approach does not account for energy dissipation due to non-linear parts of the deformation in the slab and/or weak layer, which would undoubtedly decrease the amount of strain energy available for crack propagation.
\end{abstract}

KEYWORDS: fracture mechanics, snow avalanche, snow fracture, snow mechanical properties

\section{INTRODUCTION}

Snow slab avalanche release occurs as the result of failure initiation and crack propagation along a weak layer buried in the snowpack. When an initial crack in the weak layer reaches a critical size $r_{\mathrm{C}}$ it rapidly propagates resulting in the progressive fracture of the weak layer inducing its volumetric collapse (e.g. van Herwijnen and others, 2010). Avalanche release is thus a fracture mechanical process (e.g. McClung, 1981).

The theory of fracture mechanics describes the separation of solids due to crack growth under external loading (e.g. Anderson, 1995). While the theory of fracture mechanics is far from complete, the field of linear elastic fracture mechanics has matured. Linear elasticity is the simplest form of material behavior, in which the stress and the strain in a material under uniaxial loading are related by the elastic modulus $E=\sigma / \varepsilon$. The overall aim of fracture mechanics is to assess the integrity of a structure in the presence of flaws (cracks), in particular to assess the crack size at which the energy available for crack growth exceeds the energy expended to extend the crack. To evaluate this critical crack size, it is convenient to use the energy release rate. It is defined as the rate of change in total energy per unit crack area (e.g. Anderson, 1995), i.e. a measure of the energy available to advance the crack by a unit area. Note that the energy release rate is with respect to crack length, not time. In an infinite uniform plate with a crack of length $2 r$ subjected to a stress $\sigma$, the energy release rate $G$ for linear elastic material is given by

$$
G=\frac{\pi \sigma^{2} r}{E}
$$

At the onset of spontaneous crack propagation, when $r=r_{\mathrm{C}}$ the energy release rate $G_{c}$ equals the material resistance to unstable crack propagation: $G_{\mathrm{c}}=2 w_{\mathrm{f}}$, where $w_{\mathrm{f}}$ is a material property called the specific fracture energy. It represents the energy that must be supplied to create a unit area of new crack surface (e.g. Bažant and Planas, 1998).

Applying Eqn (1) to cracks in a natural snow cover is not readily possible. First, snow is not a uniform material, as large density and microstructural depth variations are commonly observed. Interfacial fracture mechanics, which deals with crack growth between dissimilar materials, is thus more relevant to describe avalanche release (e.g. Schweizer and Camponovo, 2002). However, due to the complexity of the interface problem, there are only a few analytical solutions available for special geometries (e.g. Hutchinson and Suo, 1992). Second, snow is a highly ratedependent material, i.e. it generally does not behave like a linear elastic material. The fracture behavior of snow is thus best described as quasi-brittle, implying that the fracture 
process zone, a nonelastic zone ahead of the crack tip, is of finite size (Bažant and others, 2003; McClung, 2009). Clearly, applying linear elastic fracture mechanics to snow does not account for the complex material behavior of snow. However, applying nonlinear theories requires additional material properties, such as the size of the fracture process zone and knowledge on the post-peak failure behavior (McClung, 2015), which thus far remain unknown. Therefore, snow is still often treated as a linear elastic material. To assess the critical crack size for propagation in a layered snowpack consisting of a slab and the underlying weak snow layer, various theories have been proposed (e.g. McClung, 1979; Chiaia and others, 2008; Heierli and others, 2008; Gaume and others, 2013). These all require knowledge of two material properties, namely the elastic modulus of the slab and the specific fracture energy (or strength) of the weak layer.

Our present knowledge on the elastic modulus of snow is mainly based on laboratory experiments. Mellor (1975) reported values of the Young's modulus between 0.2 and 20 MPa for a snow density varying from 100 to $350 \mathrm{~kg} \mathrm{~m}^{-3}$. Most of these values were obtained from uniaxial compression experiments at very low strain rates $\dot{\varepsilon}$ between $8 \times 10^{-6} \mathrm{~s}^{-1}$ and $4 \times 10^{-4} \mathrm{~s}^{-1}$. More recently, Scapozza (2004) found similar values from quasi-static uniaxial compression tests (strain rate $\dot{\varepsilon}<10^{-3} \mathrm{~s}^{-1}$ ). In contrast, Sigrist (2006) found significantly higher values by conducting dynamic loading experiments at high strain rates $\dot{\varepsilon}>10^{-2} \mathrm{~s}^{-1}$, and even higher values were reported by Capelli and others (2016), obtained from acoustic wave propagation measurements. The observed differences are due to the fact that snow deformation is not purely elastic and also includes time dependent visco-plastic components, except for very fast loading rates and/or small deformations below the elastic limit. This is particularly true for experiments slower than the ductile-to-brittle transition of snow, which typically occurs for strain rates around $10^{-3} \mathrm{~s}^{-1}$ (e.g. Narita, 1980; Schweizer, 1998). Hence, quasi-static values represent an effective elastic modulus and most reported values include time dependent strain components.

With regard to weak layer specific fracture energy, far fewer measurements exist. Laboratory measurements are challenging due to the fragile nature of weak layers (Reiweger and Schweizer, 2010, 2013; Reiweger and others, 2015), and direct field measurements of the material properties of the snowpack are difficult and scarce (Föhn and others, 1998). Several studies introduced indirect methods to derive mechanical snow properties from field experiments. Sigrist and Schweizer (2007) were the first to estimate $w_{\mathrm{f}}$ with field experiments and finite element (FE) modeling. Their method requires a Propagation Saw Test (PST; van Herwijnen and Jamieson, 2005; Sigrist and Schweizer, 2007; Gauthier and Jamieson, 2008) to determine the critical cut length $r_{\mathrm{C}}$ and a snow micro-penetrometer measurement (SMP; Schneebeli and Johnson, 1998) to estimate the effective elastic modulus $E$ of the slab. While Sigrist and Schweizer (2007) reported a mean fracture energy of $0.07 \mathrm{~J} \mathrm{~m}^{-2}$, more recent results using the same methodology on eight different weak layers indicate substantially larger values, typically around $1 \mathrm{~J} \mathrm{~m}^{-2}$ (Schweizer and others, 2011). Similar values (between 0.5 and $2 \mathrm{~J} \mathrm{~m}^{-2}$ ) were also found by Reuter and others (2013) and Reuter and others (2015) by integrating the penetration force signal of the SMP over the weak layer thickness. The differences in $w_{\mathrm{f}}$ between Sigrist and Schweizer (2007) and Schweizer and others (2011) arise from lower effective moduli used in the latter, obtained by using a more recent signal processing method for analyzing SMP force signals (Marshall and Johnson, 2009; Löwe and van Herwijnen, 2012). The large differences in $w_{\mathrm{f}}$ highlight the sensitivity of this approach to the method used to estimate the effective elastic modulus and the accuracy thereof. Unfortunately, the various procedures for determining the effective elastic modulus of snow lead to incompatible results and it remains unclear which method to use. A field-based experimental approach to determine the relevant mechanical properties of the snowpack seems most appropriate to resolve this discrepancy.

By extending the previously published methodological approach and data from van Herwijnen and Heierli (2010), in this study, we report the effective elastic modulus of the slab and the specific fracture energy of the underlying weak layer for 80 different snowpack configurations. Using a video sequence of a PST, both parameters are estimated from the displacement field of the slab prior to crack propagation.

\section{METHODS}

\subsection{Field experiments and particle tracking}

We conducted 222 field experiments from 2008 to 2015 at 80 sites in Switzerland and in the USA. A PST (Gauthier and Jamieson, 2008) modified to have slope normal, rather than vertical column ends was used in the field to measure critical crack lengths. A rectangular section of snow, $0.3 \mathrm{~m}$ across the slope and $0.9-3 \mathrm{~m}$ up the slope, was isolated on all sides. Starting from the down-slope end of the column, the weak layer was cut using a snow saw until crack propagation started. Numerous black markers were inserted in the snow above and below the weak layer. To scale the images, we measured the distance between the outermost markers in the top row. Experiments were recorded with a video camera with frame rates ranging from 15 to 480 frames $\mathrm{s}^{-1}$ (fps; Table 2). A $2 \mathrm{~mm}$ thick saw was used on harder slabs, while a $5 \mathrm{~mm}$ thick saw was used on very soft slabs to avoid crack-face contact. At each field site, a snow profile was recorded, giving information about grain shape and size, layer thickness, density and hand hardness index of snowpack layers.

A particle tracking velocimetry algorithm (PTV; Crocker and Grier, 1996) was used to analyze the displacement of the markers in a coordinate system aligned with the slope (Fig. 1). Displacements $u_{x}(r)$ and $u_{y}(r)$ of each marker at cut length $r$ were measured with reference to the initial positions $x_{0}$ and $\left|y_{0}\right|$ before cutting. The uncertainty in the position measurements was determined as the standard deviation of marker positions prior to sawing (overall mean $0.08 \mathrm{~mm}$; range $0.01-0.4 \mathrm{~mm}$ ). Saw cut lengths were estimated in 5-15 key frames, depending on the frame rate and length of the video recording. Key frames were evenly distributed from the start of the experiment to the onset of crack propagation. For frames in between the key frames, the saw cut length was estimated by linear interpolation. The critical cut length $r_{\mathrm{c}}$ was determined as the saw cut length in the last frame before crack propagation.

Despite using a tripod, some unwanted camera movement was present in the majority of the experiments $(88 \%)$. Post-processing was thus required to remove the resulting spurious displacements from the marker trajectories. Specifically, the average displacements $\overline{u_{x}(r)}$ and $\overline{u_{y}(r)}$ of 

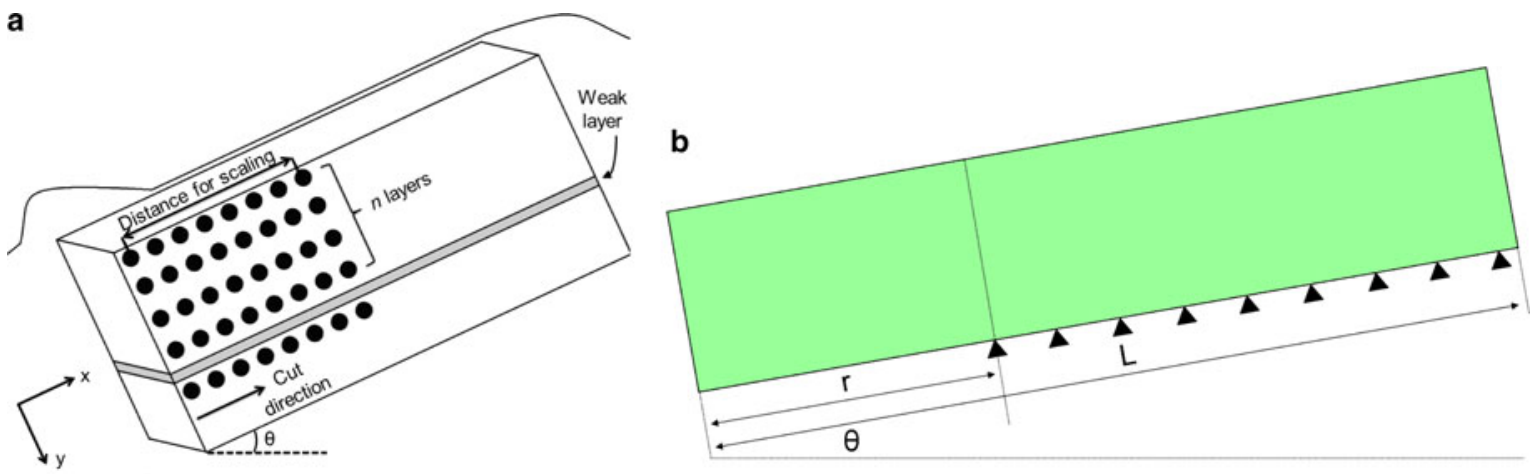

Fig. 1. (a) Schematic representation of the experimental setup and coordinate system used in the analysis with $x$ the slope parallel direction, $y$ the slope normal direction and $\theta$ the slope angle. (b) FE model setup with a snow slab of total length $L$ unsupported over the crack length $r$ and rigidly supported at the base along the remaining length $L-r$. Triangles indicate fixed nodes.

markers at the up-slope end of the snow column were subtracted from the displacements of each marker (Fig. 2). The exact number and position of the markers used for averaging was determined by visual examination of marker trajectories on a case-by-case basis.

\subsection{Derivation of mechanical properties}

To determine the effective elastic modulus of the slab and the weak layer fracture energy from the displacement fields obtained from PST experiments, we used a method based on the work by Heierli and others (2008). For the test geometry shown in Figure 1, they suggested a formulation for the energy of an edge crack of length $r$. The total energy of the system $V(r)=V_{\mathrm{f}}(r)+V_{\mathrm{m}}(r)$ consists of the fracture energy $V_{\mathrm{f}}(r)$ and the mechanical energy $V_{\mathrm{m}}(r)$. The fracture energy is the energy required to destroy the cohesion along the crack faces and is given by $V_{\mathrm{f}}(r)=w_{\mathrm{f}} r$, with $w_{\mathrm{f}}$ the weak layer specific fracture energy per unit crack surface. The mechanical energy $V_{\mathrm{m}}(r)=V_{\mathrm{e}}(r)+V_{\mathrm{p}}(r)$ consists of strain energy $V_{\mathrm{e}}(r)$ and gravitational potential energy $V_{\mathrm{p}}(r)$ and is the energy available for crack expansion.

To derive an expression for the mechanical energy $V_{\mathrm{m}}(r)$, Heierli and others (2008) assumed that changes in strain energy and gravitational potential energy of the slab are the main contributor to $V_{\mathrm{m}}(r)$ and contributions from the weak layer and substrate are negligible. Both the weak layer and the substrate are thus considered as rigid and $V_{\mathrm{m}}(r)$ can be described by two terms (see below)

$$
\begin{aligned}
V_{\mathrm{m}}(r)= & -\frac{\pi \gamma r^{2}}{4 E^{\prime}}\left(\tau^{2}+\sigma^{2}\right)-\frac{r^{3}}{6 E^{\prime} D}\left[\lambda_{\tau \tau} \tau^{2}+\lambda_{\sigma \tau} \sigma \tau\right. \\
& \left.+\lambda_{\sigma \sigma} \sigma^{2}\right]
\end{aligned}
$$
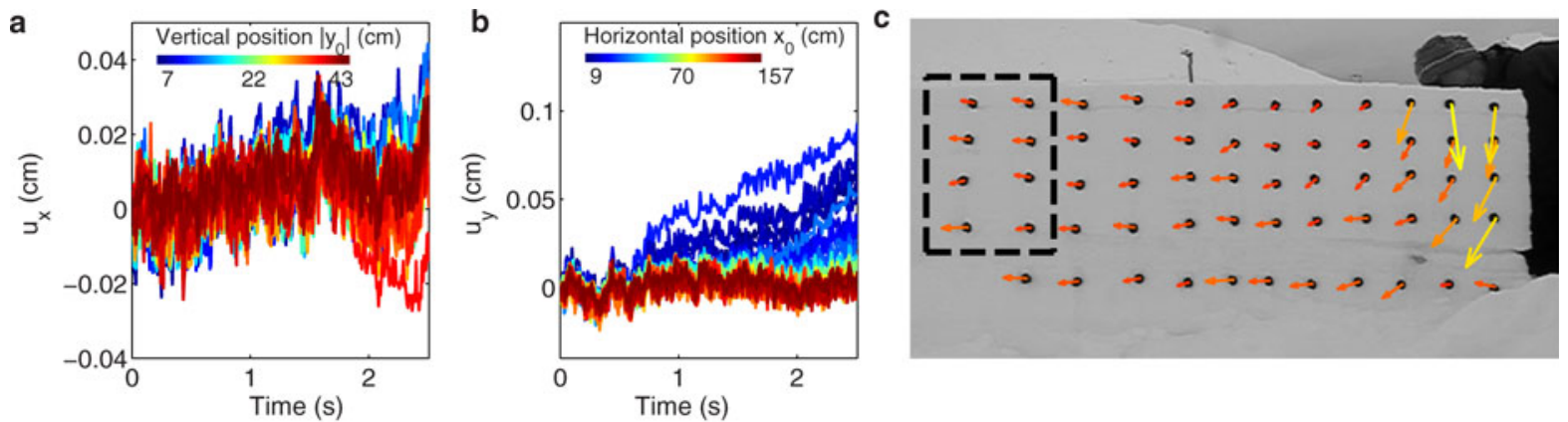

d

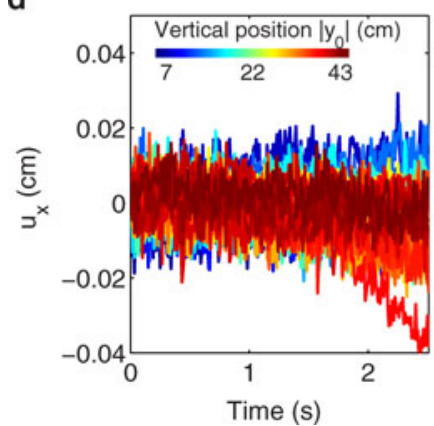

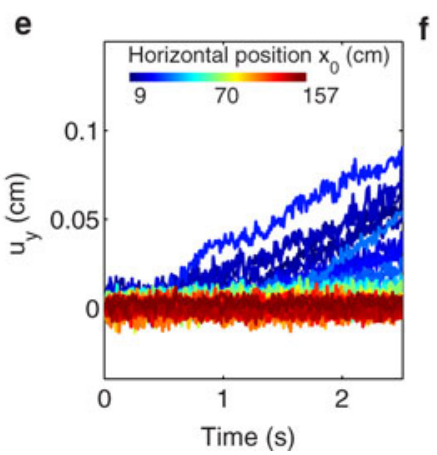

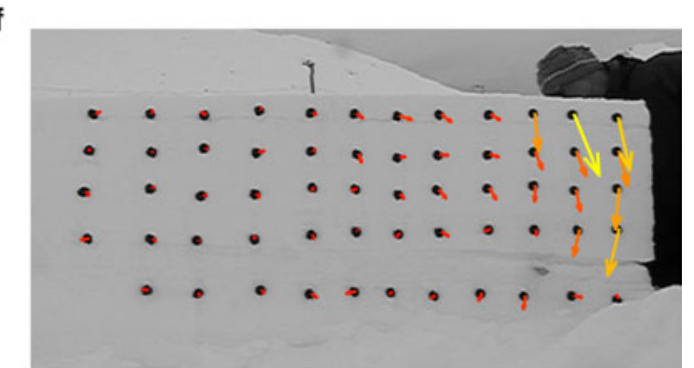

Fig. 2. Post-processing to remove spurious displacement due to camera movement. (a) Slope parallel displacement with time before correction. Colors indicate the vertical position $y_{0}$ of the markers relative to the weak layer. (b) Slope normal displacement with time before correction. Colors indicate the horizontal position $x_{0}$ of the markers relative to the right edge of the PST. (c) Displacement field at $r=r_{\mathrm{c}}$ before correction. The black dashed square shows the markers that were used to calculate the mean displacement used for correcting marker trajectories. (d), (e) and (f) displacements after correction. 
where the load on the weak layer exerted by the slab of mean density $\rho$ and thickness $D$ consists of a negative shear stress $\tau=-\rho g D \sin \theta$ and a negative compressive stress $\sigma=-\rho g D \cos \theta$. Here, $E^{\prime}=E /\left(1-v^{2}\right)$ is the plane strain elastic modulus of the slab, assumed uniform, $E$ is the elastic modulus, $v$ the Poisson's ratio (assumed $=0.2$ ) and $\gamma$ is a constant (assumed $=1$; Heierli and others, 2008). The terms in square brackets are given by

$$
\begin{gathered}
\lambda_{\tau \tau}=1+\frac{9}{4} \eta\left(\frac{r}{D}\right)^{-1}+\frac{9}{4} \eta^{2}\left(\frac{r}{D}\right)^{-2} \\
\lambda_{\sigma \tau}=\frac{9}{2} \eta+\frac{9}{2} \eta^{2}\left(\frac{r}{D}\right)^{-1} \\
\lambda_{\sigma \sigma}=3 \eta^{2}+\frac{9}{4} \eta\left(\frac{r}{D}\right)+\frac{9}{5}\left(\frac{r}{D}\right)^{2}
\end{gathered}
$$

with $\eta=\sqrt{4(1+v) / 5}$. The mechanical energy in Eqn (2) consists of two terms: a fracture mechanical and a bending term. The first term on the right-hand side is the fracture mechanical term and accounts for the elastic strain energy released by the material surrounding the crack when the crack advances. It is obtained by integrating the energy release rate $G$ of a mixed/mode interface crack between two different elastic media over $r$ (Eqn (2.29) in Hutchinson and Suo, 1992). The solution provided by Hutchinson and Suo (1992) is valid for semi-infinite elastic media, thus only for short crack lengths (i.e. $r<D$ ). For longer crack lengths, bending of the unsupported part of the slab contributes considerable strain energy. The second term in Eqn (2), which is valid for longer cracks (i.e. $r \geq D$ ), describes this contribution by considering the slab as a Timoshenko beam which is fixed to the rigid weak layer beyond the crack tip.

The mechanical energy in Eqn (2) can be estimated from the measured displacement fields. Indeed, according to the theorem of Clapeyron, for a linear-elastic system, $V_{\mathrm{m}}=V_{\mathrm{e}}-V_{\mathrm{p}}=\frac{1}{2} V_{\mathrm{p}}-V_{\mathrm{p}}=-\frac{1}{2} V_{\mathrm{p}}$, with $V_{\mathrm{e}}$ the strain energy stored in the body and $V_{p}$ the gravitational potential energy. Snow slabs are rarely uniform, and in our experiments the slab above the weak layer generally consisted of several layers with different densities. The gravitational potential energy was therefore computed by dividing the slab into $n$ layers, corresponding to the number of rows of markers in the slab (Fig. 1), of thickness $D_{\mathrm{i}}$ and density $\rho_{\mathrm{i}}$. The mechanical energy is then computed as

$$
\begin{aligned}
V_{\mathrm{m}}^{P T V}(r) & =-\frac{1}{2} V_{p}(r) \\
& =-\frac{1}{2} \sum_{i=1}^{n} \rho_{i} g D_{i}\left(\overline{u_{x, i}(r)} \sin \theta+\overline{u_{y, i}(r)} \cos \theta\right)
\end{aligned}
$$

with $\overline{u_{x, i}(r)}$ and $\overline{u_{y, i}(r)}$ the mean displacements of the markers in layer $i$. To account for slab stratigraphy, we therefore introduce an effective elastic modulus $E^{\star}$. It is defined as the modulus of a uniform slab of equal mean density and yielding the same displacement field as the real slab. To estimate $E^{\star}$, first $E^{\prime}$ is determined for which Eqn (2) most accurately fits the mechanical energy derived by Eqn (6). Then, the relation $E^{\star}=\left(1-v^{2}\right) E^{\prime}$ is used to obtain the effective elastic modulus. Once $E^{\prime}$ has been determined, the specific fracture energy is easily obtained by numerical differentiation of Eqn
(2): $w_{\mathrm{f}}=G_{\mathrm{c}}=-\left.\frac{d}{d r} V_{\mathrm{m}}(r)\right|_{r=r_{\mathrm{c}}}$. The described method can also be used to determine $E^{\star}$ only by performing a PST in which there is no crack propagation, for instance when making the saw cut within a thick uniform snow layer and not in a weak layer.

The uncertainties in the derived $E^{\star}$ and $w_{\mathrm{f}}$ values were estimated using a Monte Carlo method to account for the PTV measurement uncertainty and uncertainties associated with the observations made in the field: density $\pm 5 \%$, scaling distance measurement $\pm 1 \%$, slope angle $\pm 1^{\circ}$. By making $10^{3}$ random draws from the probability distributions for the input quantities (assumed normal), the resulting distributions were evaluated. The values of $E^{\star}$ and $w_{f}$ reported here are the mean of the respective distributions. The reported uncertainty, $\sigma_{\mathrm{E}^{\star}}$ and $\sigma_{\mathrm{w}_{\mathrm{f}}}$ respectively, is twice the standard deviation of the respective distributions, which gives a level of confidence of approximately $95 \%$.

\subsection{FE simulations}

The expression for the mechanical energy $V_{m}(r)$ in Eqn (2) was derived based on empirical evidence. Indeed, Heierli and others (2008) note that adding the fracture mechanical and the bending terms results in mechanical energy estimates that compare well with FE simulations. While Heierli and others (2008) provided some supporting evidence to confirm their statement, a thorough validation is still required to investigate the reliability of Eqn (2) for a parameter range typically encountered in field experiments.

For this parametric study we used FE simulations to model the displacement of a snow slab bending over the edge of a rigid substrate, similar to the model setup employed by Reuter and others (2015). In the model, a snow slab is rigidly supported at its base and unsupported along the crack length $r$ (Fig. 1b). The slab has uniform material properties and is inclined at a slope angle $\theta$. The same boundary conditions and model geometry were chosen as Heierli and others (2008) described to derive Eqn (2). The model domain was divided into 2-D, quadrilateral plane strain elements with eight nodes each. The mesh consisted of 100 nodes $\mathrm{m}^{-1}$ in the vertical and horizontal direction, but node density was increased to 500 nodes $\mathrm{m}^{-1}$ in the unsupported section. The input parameters included slope angle, elastic modulus, Poisson's ratio (fixed value of 0.2 ), slab density, slab thickness, crack length and length of the beam (fixed at $10 \mathrm{~m}$ to avoid edge effects). The model system was loaded by gravity and solved in ANSYS workbench to obtain the total strain energy for a given crack length $r$. The FE simulation was run once for a system with a crack of size $r$, and once with a very short crack of $r=0.01 \mathrm{~m}$. The difference in strain energy between these two states was termed $V_{\mathrm{m}}^{\mathrm{FEM}}(r)$ and compared with Eqn (2).

\section{RESULTS}

\subsection{Sensitivity study of Eqn (2)}

We performed $120 \mathrm{FE}$ simulations to investigate the influence of slab density $\rho$, slab thickness $D$, crack length $r$, elastic modulus $E$ and slope angle $\theta$ on the accuracy of the mechanical energy computed with Eqn (2). Overall, numerically obtained $V_{m}^{\mathrm{FEM}}(r)$ values were larger than those obtained with Eqn (2), up to a factor 2 (Fig. 3). While the elastic 
a

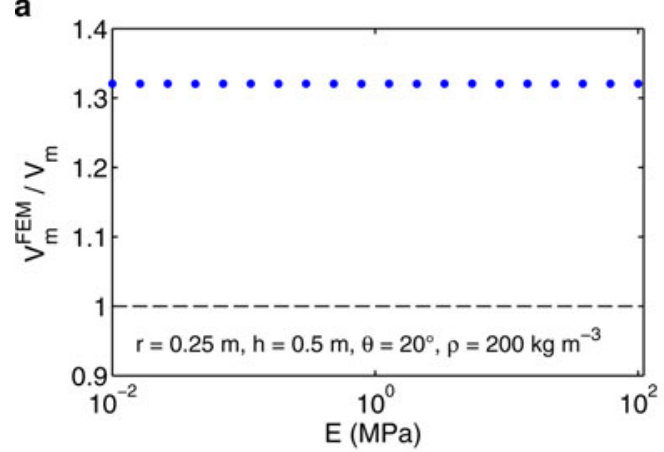

c

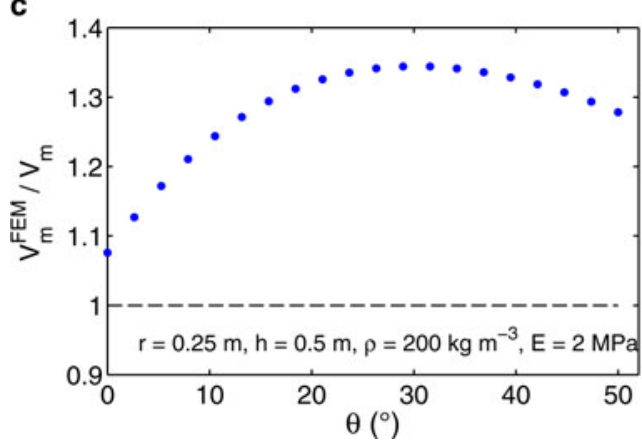

b

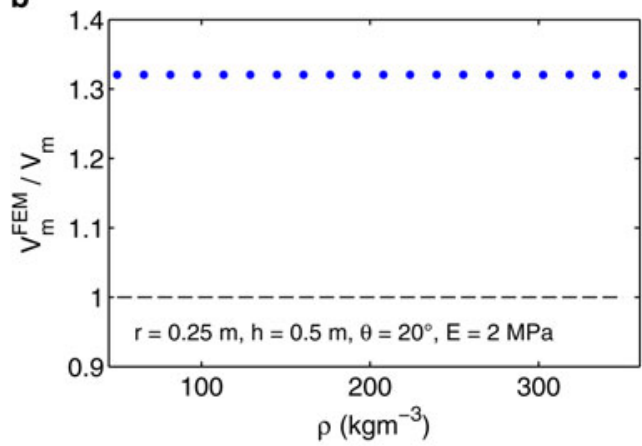

d

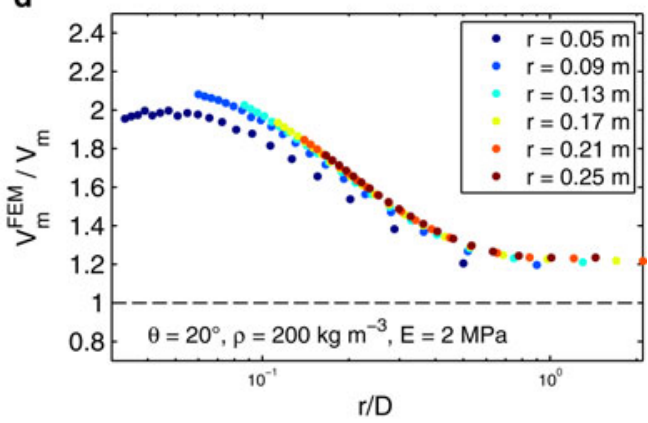

Fig. 3. Ratio (dots) between numerically obtained mechanical energy $V_{\mathrm{m}}^{F E M}(r)$ and $V_{\mathrm{m}}(r)$ obtained with Eqn (2) for various input parameters. A ratio of one (black dashed line) would mean perfect agreement. (a) $V_{\mathrm{m}}^{F E M}(r) / V_{\mathrm{m}}(r)$ with elastic modulus $E$. (b) $V_{\mathrm{m}}^{F E M}(r) / V_{\mathrm{m}}(r)$ with density $\rho$. (c) $V_{\mathrm{m}}^{F E M}(r) / V_{\mathrm{m}}(r)$ with slope angle $\theta$. (d) $V_{\mathrm{m}}^{F E M}(r) / V_{\mathrm{m}}(r)$ with the ratio between crack length $r$ and slab thickness $D$. Colors indicate the crack length.

modulus and density of the slab did not influence the results (Figs $3 a, b)$, slope angle and the ratio $r / D$ substantially influenced the accuracy of Eqn (2) (Figs 3c, d). Indeed, $V_{\mathrm{m}}^{\mathrm{FEM}}(r) / V_{\mathrm{m}}(r)$ increased with $\theta$ and decreased with $r / D$. There was also a weak influence of $r$, however only for very short crack lengths (Table 1; colors in Fig. 3d). Compared with the sensitivity to $\theta$ and $r / D$, the influence of $r$ was deemed negligible.

To investigate the influence of $\theta$ and $r / D$ in more detail, we carried out an additional $1430 \mathrm{FE}$ simulations (Table 1; Fig. 4). Again, $V_{\mathrm{m}}^{\mathrm{FEM}}(r)$ values were larger than those obtained with Eqn (2), except for $r / D<0.05$, a value recorded in only one field experiments. The influence of $\theta$ decreased with increasing $r / D$, in particular for $r / D>1$, values encountered only in $\sim 10 \%$ of our field experiments. Clearly, for realistic $r / D$ values (Table 2 ; black dots in Fig. 4c), the sensitivity of the mechanical energy computed with Eqn (2) to $\theta$ and $r / D$ has to be accounted for. To obtain more reliable effective elastic modulus estimates, we therefore used the adjusted mechanical energy

$$
V_{\mathrm{m}}^{*}(r)=Y(r / D, \theta) V_{\mathrm{m}}(r),
$$

Table 1. Overview of range of input parameters used in the FE simulations

\begin{tabular}{lllll}
\hline & $\theta$ & $R$ & $D$ & $r / D$ \\
& 0 & $\mathrm{~cm}$ & $\mathrm{~cm}$ & \\
\hline Figure 3d & 20 & $5-25$ & $10-150$ & $0.03-2.5$ \\
Figure 4 & $0-60$ & $1-100$ & 50 & $0.02-2$
\end{tabular}

$\theta$ : slope angle; $r$ : crack length; $D$ : slab thickness; $r / D$ : ratio between crack length and slab thickness. with $V_{\mathrm{m}}(r)$ the mechanical energy obtained with Eqn (2) and $Y(r / D, \theta)$ a correction factor that was extracted from a lookup table based on the FE simulations (Fig. 4c).

\subsection{Measured displacement fields}

Displacement fields were analyzed in 222 PSTs at 80 sites covering a wide range of slab and weak layer properties (Tables 2 and 3). The observed displacement fields were characteristic of slab bending in several aspects (Fig. 5). First, the displacement in the unsupported part of the slab steadily increased with increasing $r$ (Figs $5 \mathrm{a}, \mathrm{b}$ before 2.8 $\mathrm{s})$. Second, slope-normal displacement $u_{y}\left(x_{0}, y_{0}\right)$ was independent of $\left|y_{0}\right|$ (Fig. 5c) and decreased with increasing $x_{0}$ (Fig. 5b). Third, slope-parallel displacement $u_{x}\left(x_{0}, y_{0}\right)$ was very close to zero or positive (upslope) immediately above the weak layer $\left(y_{0}=0\right)$ and negative (downslope) close to the snow surface (Fig. 5a). For $x_{0}>r_{\mathrm{c}}$, the displacement decreased with $x_{0}$ (Fig. 5c). On average, at the critical cut length $r_{\mathrm{c}}, u_{\mathrm{y}}$ decreased from $\sim 0.6 \mathrm{~mm}$ at $x_{0}=0$ to $\sim 0.2 \mathrm{~mm}$ at $x_{0}=r_{\mathrm{C}}$ and vanished near $x_{0}=2 r_{\mathrm{C}}$ (black curve in Fig. 6). In other words, there was slope normal displacement beyond the crack tip, typically up to a distance of $2 r_{\mathrm{c}}$. The displacements of the markers in the substrate were indistinguishable from the background noise (Figs $2 \mathrm{f}$ and $5 \mathrm{c}$ ) indicating that the substrate does not notably deform during a PST.

It has been suggested that time dependent deformation of the snow slab needs to be accounted for in PSTs (e.g. McClung, 2009). In order to investigate this issue, the timedependency of test results was examined by performing 52 side-by-side PST experiments on a weak layer of depth hoar on 15 February 2010. In half these experiments the cut speed was fast $\left(<1 \mathrm{~s}\right.$ to $\left.r_{\mathrm{c}}\right)$, while in the other experiments the cut speed was slow $\left(>30 \mathrm{~s}\right.$ to $\left.r_{\mathrm{c}}\right)$. There was no significant 

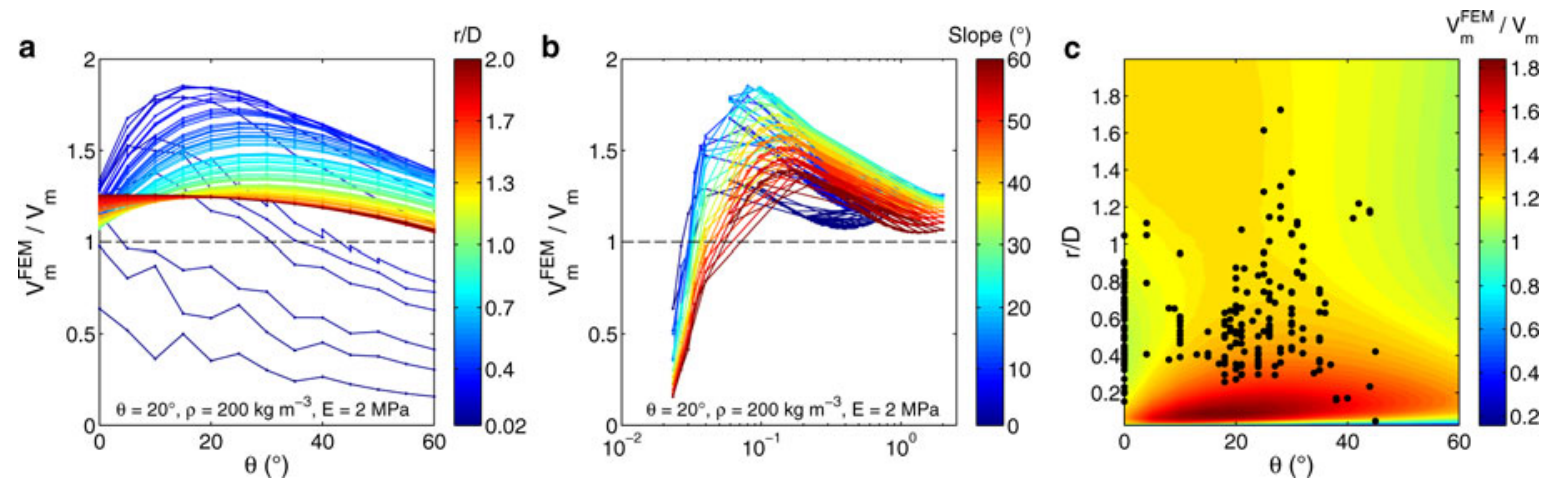

Fig. 4. (a) Ratio (dotted curves) between numerically obtained mechanical energy $V_{\mathrm{m}}^{F E M}(r)$ and $V_{\mathrm{m}}(r)$ obtained using Eqn (2) with slope angle $\theta$. Colors indicate the ratio between crack length $r$ and slab thickness $D$. (b) $V_{\mathrm{m}}^{F E M}(r) / V_{\mathrm{m}}(r)$ with $r / D$. Colors indicate $\theta$. (c) Contour plot of $V_{\mathrm{m}}^{\text {FEM }}(r) / V_{\mathrm{m}}(r)$ with $r / D$ and $\theta$. The black dots represent the PST experiments.

Table 2. Overview of range of experimental parameters, effective elastic modulus of the slab $E^{\star}$ and weak layer specific fracture energy $w_{\mathrm{f}}$. fps: frame rate of the recordings; $\theta$ : slope angle; $\rho$ : average slab density; $D$ : slope normal slab thickness; $r_{\mathrm{c}}$ : mean critical cut length

\begin{tabular}{|c|c|c|c|c|c|c|c|c|}
\hline & $\begin{array}{l}\text { fps } \\
s^{-1}\end{array}$ & $\begin{array}{l}\Theta \\
\circ\end{array}$ & $\begin{array}{l}\rho \\
\mathrm{kg} \mathrm{m}^{-3}\end{array}$ & $\begin{array}{l}D \\
\mathrm{~cm}\end{array}$ & $\begin{array}{l}r_{\mathrm{c}} \\
\mathrm{cm}\end{array}$ & $r_{\mathrm{c}} / D$ & $\begin{array}{l}E^{\star} \\
\mathrm{MPa}\end{array}$ & $\begin{array}{l}w_{\mathrm{f}} \\
\mathrm{J} \mathrm{m}^{-2}\end{array}$ \\
\hline Min & 15 & 0 & 73 & 16 & 2 & 0.05 & 0.08 & 0.08 \\
\hline Median & 120 & 20 & 201 & 49 & 28 & 0.5 & 3 & 0.4 \\
\hline Max & 480 & 45 & 316 & 148 & 89 & 1.8 & 34 & 2.7 \\
\hline
\end{tabular}

Table 3. Percentage of tested weak layers by grain type, according to Fierz and others (2009)

\begin{tabular}{lllllll}
\hline PP & DF & RG & FC & FCxr & DH & SH \\
\hline $2.9 \%$ & $2.9 \%$ & $0.5 \%$ & $16.4 \%$ & $31.4 \%$ & $6.3 \%$ & $39.6 \%$
\end{tabular}

$\mathrm{PP}$, precipitation particles; $\mathrm{DF}$, decomposing and fragmented precipitation particles; RG, rounded grains; FC, faceted crystals; FCxr, rounding faceted particles; $\mathrm{DH}$, depth hoar; $\mathrm{SH}$, surface hoar. difference in $r_{\mathrm{c}}$ for fast cut speeds $\left(r_{\mathrm{c}}=26 \pm 6 \mathrm{~cm}\right)$ and slow cut speeds $\left(r_{\mathrm{C}}=24 \pm 7 \mathrm{~cm}\right.$; T-test $\left.p=0.22\right)$.

\subsection{Derived mechanical properties}

The largest observed slope normal displacements prior to crack propagation were generally on the order of $1 \mathrm{~mm}$ or less (Fig. 6). In comparison, the mean uncertainty of the position measurements by the PTV method was $0.08 \mathrm{~mm}$. Considerable scatter in the derived mechanical energy was therefore present, as seen in Figure 7 for the experiment shown in Figure 5. Nevertheless, the trend in $V_{m}^{*}(r)$ was clear and generally well described by Eqns (2) and (7). For the example shown in Figure 7, the normalized root-meansquared error (NRMSE; normalized with $V_{\mathrm{m}}^{\text {PTV }}\left(r=r_{\mathrm{c}}\right)$ ) was $12 \%$. Overall, the NRMSE ranged from 4 to $38 \%$ with a mean of $15 \%$ and significantly decreased with increasing $r$ / $D$ ratio (Spearman $r=0.29, p<0.01$ ).

Overall, we estimated $E^{\star}$ in 222 PSTs and it ranged from 0.08 to $34 \mathrm{MPa}$ with a median of $3 \mathrm{MPa}$ (Table 2). We estimated $w_{\mathrm{f}}$ in 206 PSTs and it ranged from 0.08 to $2.7 \mathrm{~J} \mathrm{~m}^{-2}$ with a median of $0.4 \mathrm{~J} \mathrm{~m}^{-2}$. The mean uncertainty in the derived $E^{\star}$ values was $\sim 25 \%$ (range from 20 to $67 \%$ ), and the mean uncertainty in $w_{\mathrm{f}}$ was $16 \%$ (range from 6 to $50 \%$ ). In about half of the experiments, the crack
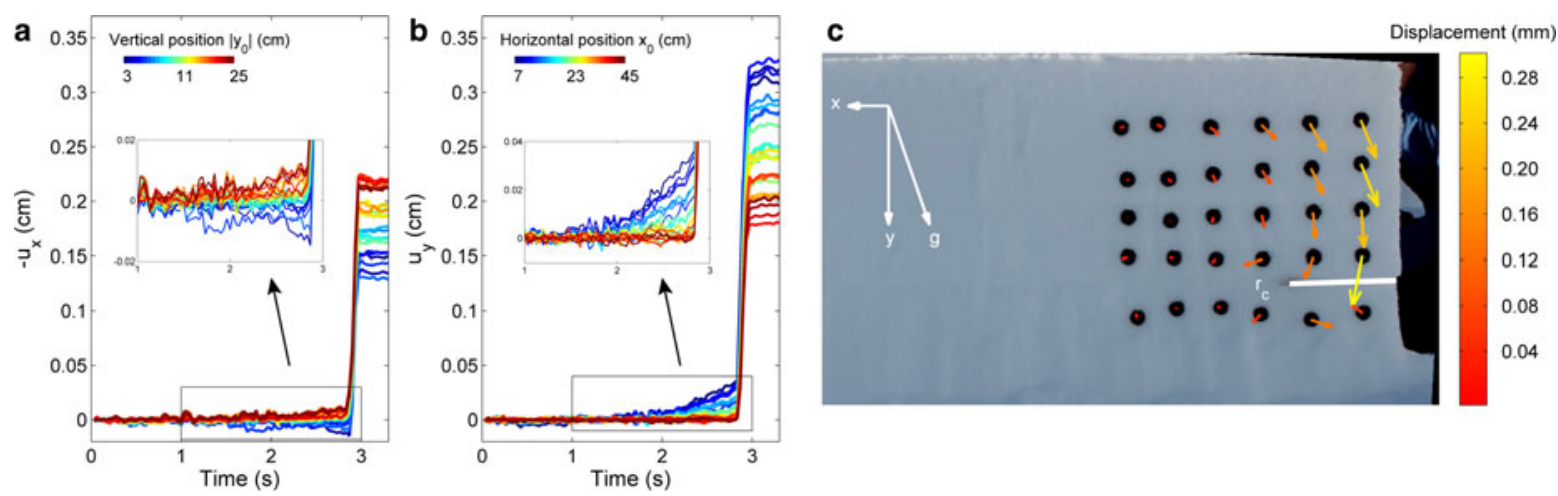

Fig. 5. Displacement measurements for a PST performed on a weak layer consisting of rounding faceted particles with $\theta=19^{\circ}, D=36 \mathrm{~cm}$, $\rho_{\text {slab }}=226 \mathrm{~kg} \mathrm{~m}^{-3}$ and $r_{\mathrm{c}}=20 \mathrm{~cm}$. (a) Negative slope parallel displacement with time. Colors indicate the vertical position $\left|y_{0}\right|$ of the markers relative to the weak layer. (b) Slope normal displacement with time. Colors indicate the horizontal position $x_{0}$ of the markers relative to the right edge of the PST. The insets represent a zoom of the bending phase before the onset of crack propagation. (c) Displacement field at $r=r_{\mathrm{c}}$. The direction of gravity is indicated with the arrow, which, for scale, is $20 \mathrm{~cm}$ long. 


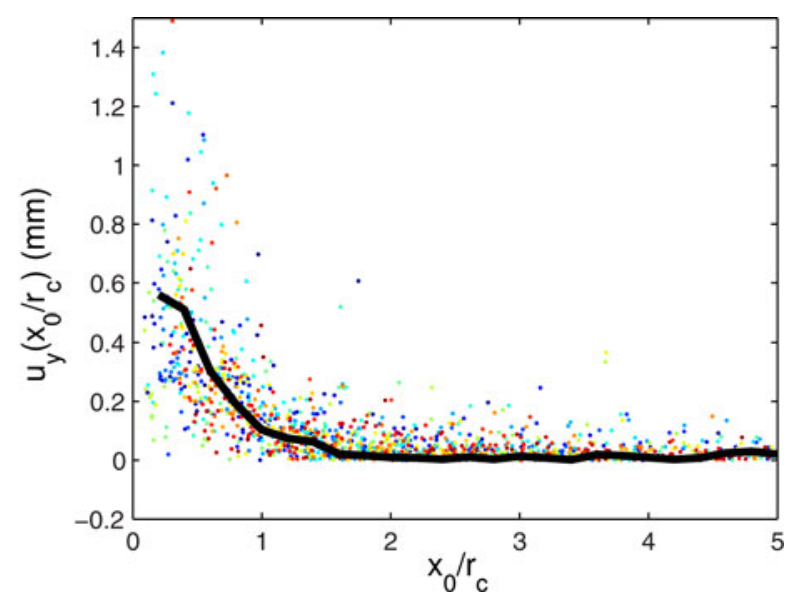

Fig. 6. Slope normal displacement $u_{\mathrm{y}}$ with normalized distance $x_{0} / r_{\mathrm{c}}$ for all 222 tests (each color represent one test) at the critical cut length $r=r_{\mathrm{c}}$, i.e. the onset of crack propagation. The mean slope normal displacement of all experiments is depicted by the thick black curve.

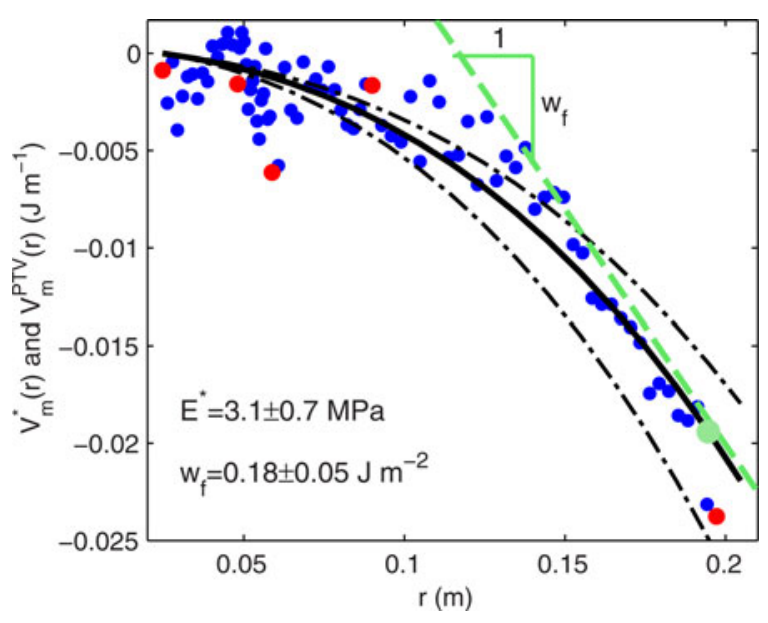

Fig. 7. Derived mechanical energy with crack length $r$ for the experiment shown in Figure 5. The red dots represent the key frames at which the saw cut length $r$ was estimated from the images. The black line represents the best fit of $V_{\mathrm{m}}^{*}(r)$ (Eqn (7)) to the experimental data $V_{\mathrm{m}}^{\mathrm{PTV}}(r)$ (Eqn (6), blue dots), and the black dashed-dotted lines the $95 \%$ confidence interval. The green dashed line represents the tangent to the mechanical energy at $r=r_{\mathrm{C}}=0.2 \mathrm{~m}$.

propagated to the end of the snow sample (106 of 222 experiments), while in the remaining experiments fracture arrest was observed. Interestingly, $E^{\star}$ was significantly lower for experiments in which cracks arrested (median 2.1 $\mathrm{MPa}$ ) than for experiments in which the crack propagated to the very end (median 3.6 MPa; $U$-test $p<0.01$ ), in line with recent experimental and numerical results (Birkeland and van Herwijnen, 2014; Schweizer and others, 2014). In contrast, $w_{\mathrm{f}}$ was similar in cases of fracture arrest (median $0.44 \mathrm{~J} \mathrm{~m}^{-2}$ ) and in cases where the crack propagated (median $0.42 \mathrm{~J} \mathrm{~m}^{-2}$ ).

In general, $E^{\star}$ correlated well with mean slab density (Spearman $r=0.69, p<0.01$; Fig. 8). A reasonable fit to the experimental data (NRMSE of $13 \%$; blue dashed curve

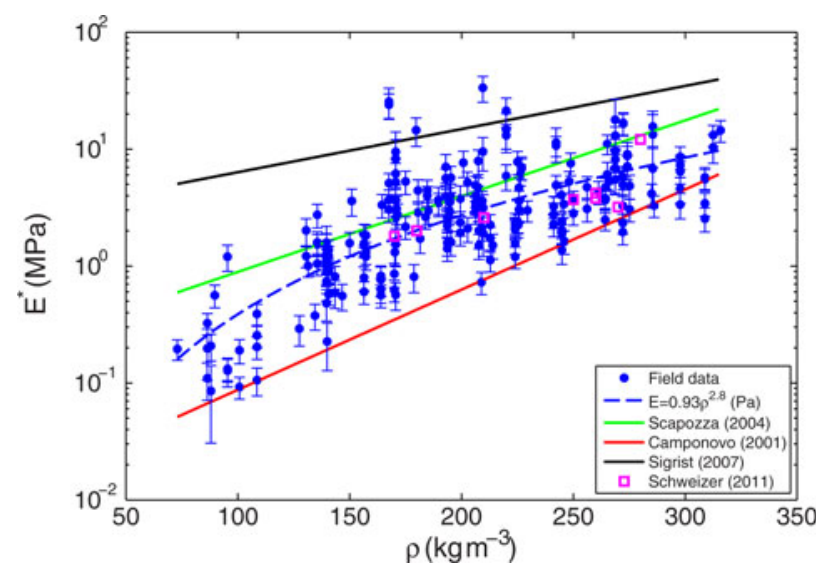

Fig. 8. Effective elastic modulus $E^{\star}$ with slab density. Field data (blue dots) and power law fit (blue dashed curve). Also shown are the parameterizations from laboratory studies presented in Scapozza (2004) (green line), Camponovo and Schweizer (2001) (red line) and Sigrist (2006) (black line) as well as estimates from SMP measurements (squares) from Schweizer and others (2011).

in Fig. 8) was given by the empirical power law,

$$
E(\rho)=0.93 \rho^{2.8}[\mathrm{~Pa}] .
$$

Most of our measurements fell between the empirical model reported by Scapozza (2004) based on laboratory measurements on 200 uniform snow samples (green line in Fig. 8), and the model reported by Camponovo and Schweizer (2001) based on laboratory measurements performed at $1 \mathrm{~Hz}$ (red line in Fig. 8). However, the model reported by Sigrist (2006) based on cyclic loading experiments at $100 \mathrm{~Hz}$ (black line in Fig. 8) resulted in larger $E^{\star}$ values than almost all of our measurements.

There was a weak negative correlation between weak layer specific fracture energy $w_{\mathrm{f}}$ and slope angle (Spearman $r=-0.2, p<0.01)$. On the other hand, $w_{\mathrm{f}}$ significantly correlated with the total overlying stress $\sigma_{0}=\sqrt{\tau^{2}+\sigma^{2}}=\rho g D$ (Spearman $r=0.51, p<0.01$; Fig. 9b). Finally, $w_{\mathrm{f}}$ values showed some dependence on grain type (Fig. 9a). While most of the investigated weak layers consisted of persistent grains (FC, FCxr, DH and $\mathrm{SH}$ in Table 3), there were also six weak layers of precipitation particles (PP) and 7 layers of decomposed and fragmented precipitation particles or rounded grains (DF/RG). The median weak layer specific fracture energy was highest for DF/RG and DH, while the lowest values of $w_{\mathrm{f}}$ were associated with PP.

\subsection{Reproducibility}

At 53 sites, more than one PST was performed. To investigate the reliability of the measurements, we therefore determined the mean measurement uncertainty for each site, defined as $\overline{\sigma_{\mathrm{E}}}=\sqrt{\frac{1}{n} \sum_{i=1}^{n} \sigma_{\mathrm{E}^{*}, i}^{2}}$ and $\overline{\sigma_{\mathrm{w}_{\mathrm{f}}}}=\sqrt{\frac{1}{n} \sum_{i=1}^{n} \sigma_{\mathrm{w}_{\mathrm{f}}, i^{\prime}}^{2}}$ with $n$ the number of measurements at the site. We also determined the uncertainty in the mean $\Delta E^{\star}$ and $\Delta w_{\mathrm{f}}$ for each site, defined as $R / 2 \sqrt{n}$ where the range $R$ is the difference between the maximum and the minimum values of $E^{\star}$ and $w_{\mathrm{f}}$, respectively. If the uncertainty in the mean was $>1.25$ times the mean uncertainty, we considered the measurement not reproducible. 

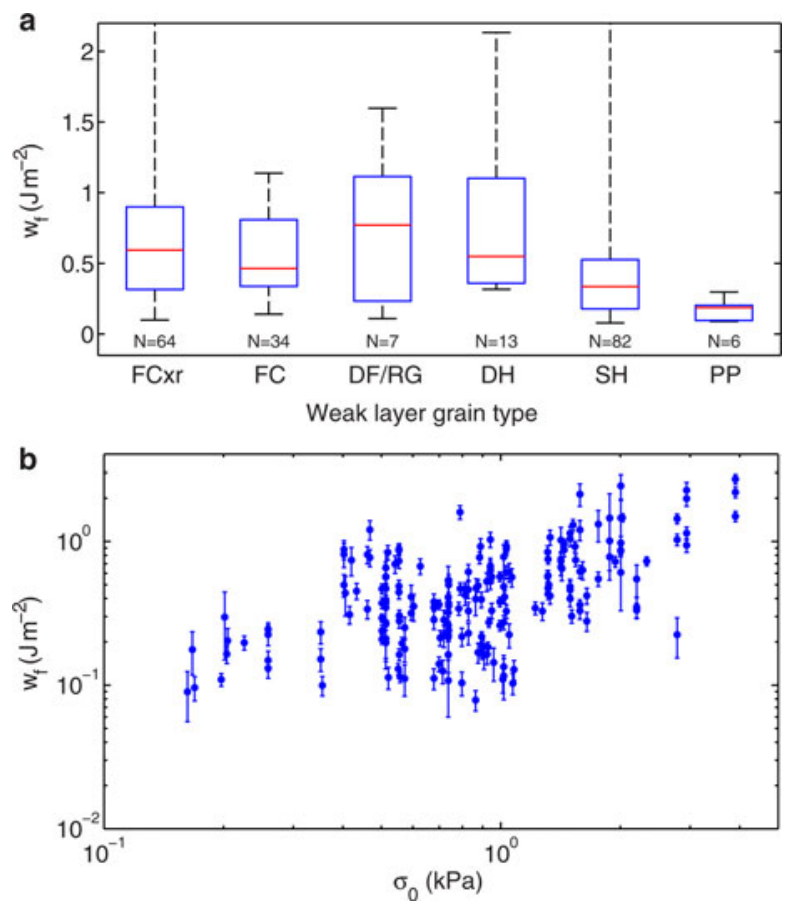

Fig. 9. (a) Weak layer specific fracture energy by grain type. On each box, the central line is the median, the edges of the box are the 1 st and 3rd quartiles, the whiskers extend to the most extreme data points. (b) Weak layer specific fracture energy vs total overlying stress $\sigma_{0}=\rho g D$.

At $92 \%$ (49 out of 53 ) of the sites with more than one PST, $\Delta E^{\star} \leq 1.25 \overline{\sigma_{\mathrm{E}^{\star}}}$, suggesting very good reproducibility of the obtained $E^{\star}$ values in nearby locations. The reproducibility for $w_{\mathrm{f}}$ was substantially poorer, since at only $46 \%$ (22 out of 48) of the sites $\Delta w_{\mathrm{f}} \leq 1.25 \overline{\sigma_{\mathrm{w}_{\mathrm{f}}}}$ (blue dots in Fig. 10).
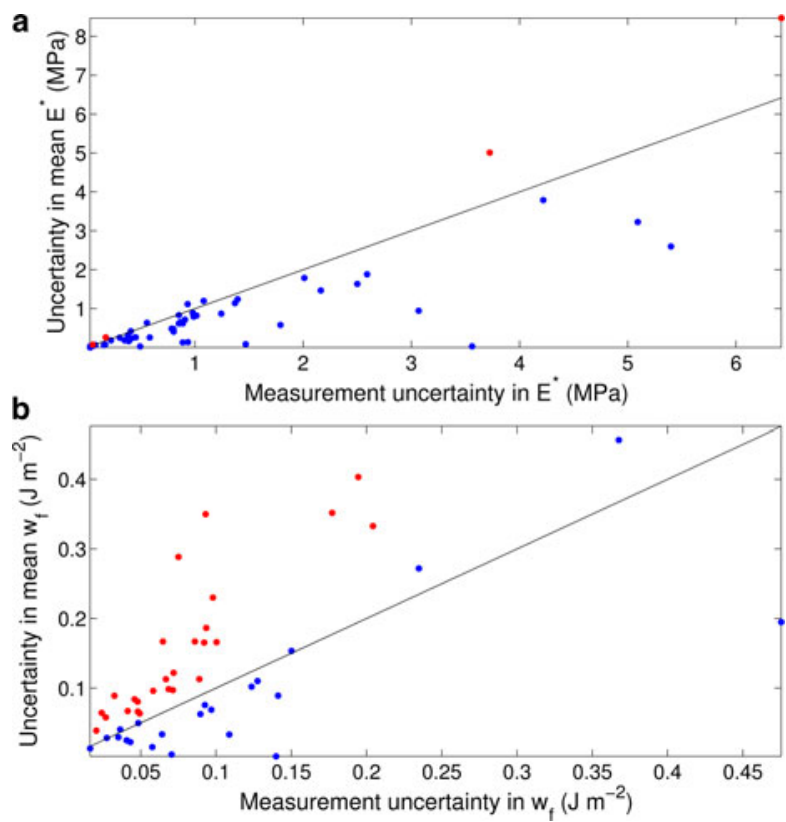

Fig. 10. (a) Uncertainty in the mean effective elastic modulus $E^{\star}$ with mean measurement uncertainty at sites with more than one PST. The black line shows the one-to-one relation. Red dots show sites where the uncertainty in the mean was larger than 1.25 the mean measurement uncertainty. (b) Same as in (a) for the weak layer specific fracture energy $w_{\mathrm{f}}$.

\section{DISCUSSION}

A recently developed method was applied to determine the weak layer specific fracture energy $w_{\mathrm{f}}$ and the effective elastic modulus of the overlying snow slab $E^{\star}$ from 222 field experiments at 80 sites by considering slab bending in a PST (van Herwijnen and Heierli, 2010). By cutting with a snow saw into the weak layer below the slab, the unsupported part of the slab bends and the corresponding displacement field prior to the onset of crack propagation was analyzed using particle tracking velocimetry. From changes in the mechanical energy with increasing crack length we estimated an effective elastic modulus of the slab and weak layer specific fracture energy based on an analytical expression (Heierli and others, 2008).

To assess the accuracy of this analytical expression, we conducted a parametric study using FE simulations. Results showed that the analytical energy formulation is most accurate for long cracks, i.e. $r \gg D$, and is sensitive to slope angle $\theta$ and $r / D$. The strong sensitivity to $r / D$ was somewhat expected, since the bending term in Eqn (2) becomes dominant for $r \gg D$. However, for typical values found in the field experiments, i.e. $r \leq D$ and $0^{\circ} \leq \theta \leq 45^{\circ}$, a correction factor was thus required to obtain an adjusted mechanical energy in line with the FE simulations (Eqn (7) and Figure 4).

A number of assumptions were made to derive the expression for the mechanical energy provided by Heierli and others (2008), in particular (1) brittle fracture, (2) linear elastic behavior of the slab and (3) a rigid substrate. This first assumption relates to the weak layer failure mechanism, which is not clearly defined. It is important to point out that the exact failure mechanism, in terms of defining a failure envelope for the weak layer, is not needed here since the energy required to advance the crack per unit area is given by $w_{\mathrm{f}}$, regardless of the failure mechanism. Nevertheless, the fracture is assumed to occur under mixed mode loading and since it is brittle, negligible plastic deformation is assumed to take place prior to fracture. It has been argued that snow is a quasi-brittle material (e.g. Bažant and others, 2003; McClung, 2009), and the existence of a finite fracture process zone around the crack tip, in which plastic deformation takes place, has to be accounted for. However, for critical crack lengths typically encountered in field experiments, Gaume and others (2014) recently showed that both approaches lead to very comparable results.

The latter two assumptions, namely linear elastic behavior of the slab and a rigid substrate, were required to derive an expression for the mechanical energy with crack length $r$ (Eqn (2)). The principal underlying assumption here is that changes in strain energy and gravitational potential energy of the slab are the main contributors to the overall energy of the system and are much larger than the contributions from the weak layer and the substrate. Our measurements show that the displacement in the snowpack layers below the weak layer was indistinguishable from the background noise (Figs $2 \mathrm{f}$ and $5 \mathrm{c}$ ). Furthermore, the observed displacement fields clearly show slab bending prior to crack propagation, suggesting that substantial potential energy is available for crack propagation. While it is clear that we cannot confirm which part of the displacement observed in the experiments is associated with recoverable (elastic) deformation, overall our results suggest that the assumptions made to derive the expression for the mechanical energy seem valid, at the very least as a first approximation. Thus, applying 
the theory of Heierli and others (2008) to analyze our experimental data is appropriate to obtain first order estimates of $E^{\star}$ and $w_{\mathrm{f}}$ from in-situ field tests.

Regarding the determination of the effective elastic modulus of the slab, various experimental procedures exist to determine $E^{\star}$ values. Depending on the experimental procedure, mainly the applied loading or deformation rate, differences by a factor of 10 or more are possible (e.g. Camponovo and Schweizer, 2001; Scapozza, 2004; Sigrist and Schweizer, 2007; Marshall and Johnson, 2009). In our field tests, the effective elastic modulus of the slab ranged from 0.08 to $34 \mathrm{MPa}$ with a median of $3 \mathrm{MPa}$, similar to values reported by Schweizer and others (2011), who estimated $E^{\star}$ values from snow micro-penetrometer measurements (squares in Fig. 8). The observed increase in $E^{\star}$ with slab density ranged between the empirical model of Scapozza (2004) and that of Camponovo and Schweizer (2001), whereas the model used by Sigrist and Schweizer (2007) predicts much higher elastic moduli (Fig. 8). The experiments conducted by Scapozza (2004) and Camponovo and Schweizer (2001) were performed at low strain rates $\left(\dot{\varepsilon}<10^{-3} \mathrm{~s}^{-1}\right)$, whereas Sigrist and Schweizer (2007) reported values obtained with a dynamic method at $100 \mathrm{~Hz}$. For the field experiments, the strain rate can roughly be approximated as $\dot{\varepsilon}=\left(u_{y, \max } / r_{c} \Delta t\right)$, with $u_{y, \max }$ the maximum observed slope normal displacement at $r=r_{\mathrm{C}}$ and $\Delta t$ the time required to reach the critical crack length. In our field test, $\dot{\varepsilon}$ ranged from $6 \times 10^{-5} \mathrm{~s}^{-1}$ to $2 \times 10^{-2} \mathrm{~s}^{-1}$ with a mean of $10^{-3} \mathrm{~s}^{-1}$, in line with the range of $E^{\star}$ values obtained. Results from side-by-side PST experiments with fast and slow cut speeds showed no significant differences. Nevertheless, it seems likely that given the low strain rates involved in PSTs, time-dependent strain components contribute to slab bending. Furthermore, possible plastic effects in the slab during bending, for instance local bond-breaking events, might also be present. At present, both time-dependent and plastic effects are not accounted for in the model.

Regarding the determination of the specific fracture energy of the weak layer, our $w_{f}$ values had a median value of $0.4 \mathrm{~J} \mathrm{~m}^{-2}$. The $w_{\mathrm{f}}$ data exhibited a significant dependence on total overlying stress, suggesting that $w_{\mathrm{f}}$ increases with increasing overburden. This comes as no surprise since additional load and time causes densification and pressure sintering, resulting in increased bonding (e.g. Brown and others, 2001; Szabo and Schneebeli, 2007; Podolskiy and others, 2014). Similarly, Jamieson and Johnston (2001), Zeidler and Jamieson (2006) and van Herwijnen and Miller (2013) reported a significant positive correlation between strength, overlying load and burial time for persistent and nonpersistent weak layers. Finally, our results also suggest that the lowest $w_{\mathrm{f}}$ values are generally associated with precipitation particles (Fig. 9), which is in line with the fact that these weak layers are generally very recent.

Overall, the values of the specific fracture energy are in line with recently published results by van Herwijnen and Heierli (2010), Schweizer and others (2011) and Reuter and others (2013) which ranged from 0.4 to $2.2 \mathrm{~J} \mathrm{~m}^{-2}$. On the other hand, our $w_{f}$ values are almost an order of magnitude larger than the first reported field measurement of $0.07 \mathrm{~J} \mathrm{~m}^{-2}$ by Sigrist and Schweizer (2007), or estimates from avalanche crown faces ranging from 0.001 to $0.2 \mathrm{~J}$ $\mathrm{m}^{-2}$ reported by McClung (2007) assuming simple shear fracture as fracture mechanism for slab avalanche release. These important discrepancies arise from sensitivities of these previously reported $w_{f}$ values to $E^{\star}$ estimates. To circumvent this problem, McClung (2015) recently used the cohesive crack model to estimate $w_{\mathrm{f}}$ values from avalanche crown faces $\left(0.08-0.36 \mathrm{~J} \mathrm{~m}^{-2}\right)$ and PST experiments $(0.04-$ $0.1 \mathrm{~J} \mathrm{~m}^{-2}$ ). While $E^{\star}$ estimates are not required in the cohesive crack model, the total slip at failure and the size of the fracture process zone are required, both of which cannot be measured in the field. In contrast, with the method employed here, both $w_{\mathrm{f}}$ and $E^{\star}$ are obtained directly for the measured displacement field and are independent of each other since their values are determined simultaneously from the adjusted mechanical energy function (Eqn (7)).

Recently, LeBaron and Miller (2014) used a microstructural model based on X-ray computer tomography to estimate $w_{\mathrm{f}}$, yielding values ranging between 0.005 and 0.05 $\mathrm{J} \mathrm{m}^{-2}$. In their work, the specific fracture energy was calculated by determining the energy required for breaking the bonds in the minimum cut area i.e. the path most prone to fracture. Their model thus assumed that bonds outside the minimum energy fracture path do not break. However, plastic effects outside the minimum energy path also play a role in the fracture process and should influence $w_{\mathrm{f}}$. In our approach, the assumption is made that all the energy associated with the observed deformation is available for crack propagation. Thus, any energy dissipation due to nonelastic deformation (viscous and plastic) is neglected, leading to high $w_{\mathrm{f}}$ values. Hence, our weak layer specific fracture energy values also represent effective values, including all energy sinks (elastic and plastic) in the system (LeBaron and Miller, 2014). Clearly, the high $w_{f}$ values we obtained compared with typical values for ice $(\sim 0.5-2 \mathrm{~J}$ $\mathrm{m}^{-2}$ ) suggest that a substantial fraction of the potential energy may not be available to drive crack expansion but is otherwise dissipated. In addition, displacements in the slab were found, even for $x_{0}>r_{\mathrm{C}}$ (Fig. 6) suggesting that deformation might also occur inside the weak layer and the substratum. Therefore, future work taking into account time dependent and nonlinear plastic effects in the slab as well as the mechanical properties of the weak layer and the substratum may extend the results under discussion here. Furthermore, the assumption that the mechanical energy is equal to half the work of gravity is not valid any more when nonelastic parts of deformation are included into the work function.

The measurements of the displacement field allows evaluation of the guidelines for performing a PST. Based on a statistical analysis of numerous field tests, Gauthier and Jamieson (2008) recommended that the length of a PST should be at least $1 \mathrm{~m}$, while the critical cut length should not exceed half the column length. Since the snow slab typically deformed up to a distance of $2 r_{\mathrm{C}}$ (Fig. 6), the latter recommendation is insufficient. To remove the influence of the free upslope end of the column, we suggest that the column should be sufficiently long to ensure that the critical cut length does not exceed one third of the column length. This is in line with results from Bair and others (2014) who used FE modeling to show that edge effects occur when $r_{\mathrm{C}}$ is larger than one fifth of the column length. For typical $r_{\mathrm{C}}$ values of $\sim 30 \mathrm{~cm}$, this translates to a recommended column length of at least $150 \mathrm{~cm}$. Note, however, that for studying dynamic crack propagation, even longer snow 
samples are required (van Herwijnen and others, 2010; Bair and others, 2014; Gaume and others, 2015).

The approach outlined in this paper provides a method to derive mechanical snow properties from field measurements. The consistency of results obtained in side-by-side experiments (Fig. 10) indicates that the method can be used to reliably determine the effective elastic modulus $E^{\star}$. However, poorer reproducibility was found for the weak layer specific fracture energy $w_{f}$ due to error propagation when taking the derivative of the mechanical energy. An advantage of our method is that the effective elastic modulus can be measured on snow samples in the field, including low density snow $\left(<150 \mathrm{~kg} \mathrm{~m}^{-3}\right)$ and that $w_{\mathrm{f}}$ and $E^{\star}$ as well as other fracture mechanical properties such as collapse height, propagation speed and crack-face friction, can be extracted from the same field data (van Herwijnen and Jamieson, 2005; van Herwijnen and Heierli, 2009; van Herwijnen and others, 2010; Bair and others, 2012).

\section{CONCLUSION}

We evaluated both the slab effective elastic modulus and the weak layer specific fracture energy from a single field experiment. Artificial cracks were induced in the weak layer using a saw, which caused bending of the slab prior to crack propagation. The method consists of analyzing the resulting displacement field in the slab using particle tracking velocimetry. Then the mechanical energy of the system is computed from the measured displacement field and fitted to an adjusted analytical expression allowing the determination of the effective elastic modulus of the slab and the weak layer specific fracture energy. We present these essential snow properties for 80 different snowpack configurations including persistent as well as nonpersistent weak layers. The effective elastic modulus ranged from 0.08 to $34 \mathrm{MPa}$ and increased with mean slab density according to a power law relationship. The weak layer specific fracture energy ranged from 0.08 to $2.7 \mathrm{~J} \mathrm{~m}^{-2}$ and increased with increasing load. An analysis of the measurement uncertainties highlighted the robustness of the effective elastic modulus estimates but also showed a poorer reproducibility of obtained weak layer specific fracture energy values.

In the future, accounting for visco-plastic effects in the slab and in the weak layer will be required to refine the presented results and relax the stringent assumptions of the model, namely the purely elastic behavior of the slab and the rigid character of the weak layer and the substrate.

\section{ACKNOWLEDGEMENTS}

We acknowledge the contribution of Joachim Heierli. Furthermore, we would like to thank Sascha Bellaire, Achille Capelli, Stephan Harvey, Matthias Heck, Susanna Mitterer, Christoph Mitterer, Ron Simenhois, Stephan Simioni and Franziska Zahner for assistance with field work. Finally, we are grateful for the comments by three anonymous reviewers that helped to improve the manuscript.

\section{REFERENCES}

Anderson T (1995) Fracture mechanics: fundamentals and applications. CRC Press, Boca Raton, USA
Bair E, Simenhois R, Birkeland K and Dozier J (2012) A field study on failure of storm snow slab avalanches. Cold Reg. Sci. Technol., 79-80, 20-28 (doi: 10.1016/j.coldregions.2012.02.007)

Bair E, Simenhois R, van Herwijnen A and Birkeland K (2014) The influence of edge effects on crack propagation in snow stability tests. Cryosphere, 8, 1407-1418 (doi: 10.5194/tcd-8-229-2014)

Bažant ZP and Planas J (1998) Fracture and size effect in concrete and other quasibrittle materials. CRC Press, Boca Raton, USA

Bažant ZP, Zi G and McClung D (2003) Size effect law and fracture mechanics of the triggering of dry snow slab avalanches. J. Geophys. Res. Solid Earth, 108, 2119 (doi: 10.1029/2002JB001884)

Birkeland K and van Herwijnen A (2014) The role of slabs and weak layers in fracture arrest. Proceedings of the 2014 International Snow Science Workshop, Banff, AB, Canada, 156-168

Brown R, Satyawali P, Lehning M and Bartelt P (2001) Modeling the changes in microstructure of snow during metamorphism. Cold Reg. Sci. Technol., 33(2-3), 91-101 (doi: 10.1016/S0165-232X (01)00032-5)

Camponovo C and Schweizer J (2001) Rheological measurements of the viscoelastic properties of snow. Ann. Glaciol., 32, 44-50 (doi: 10.3189/172756401781819148)

Capelli A, Kapil JC, Reiweger I, Or D and Schweizer J (2016) Speed and attenuation of acoustic waves in snow: laboratory experiments and modeling with biot's theory. Cold Reg. Sci. Technol., 125, 1-11 (doi: 10.1016/j.coldregions.2016.01.004)

Chiaia B, Cornetti P and Frigo B (2008) Triggering of dry snow slab avalanches: stress versus fracture mechanical approach. Cold Reg. Sci. Technol., 53(2), 170-178 (doi: 10.1016/j.coldregions.2007.08.003)

Crocker J and Grier D (1996) Methods of digital video microscopy for colloidal studies. /. Colloid Interf. Sci., 179(1), 298-310 (doi: 10.1006/jcis.1996.0217)

Fierz C and 8 others (2009) The international classification for seasonal snow on the ground. HP-VII Technical Document in Hydrology, 83. UNESCO-IHP, Paris, France, 90

Föhn P, Camponovo C and Krüsi G (1998) Mechanical and structural properties of weak snow layers measured in situ. Ann. Glaciol., 26, 1-6

Gaume J, Chambon G, Eckert N and Naaim M (2013) Influence of weak-layer heterogeneity on snow slab avalanche release: application to the evaluation of avalanche release depths. J. Glaciol., 59(215), 423-437 (doi: 10.3189/2013JoG12J161)

Gaume J and 6 others (2014) Evaluation of slope stability with respect to snowpack spatial variability. J. Geophys. Res., 119 (9), 1783-1789 (doi: 10.1002/2014JF003193)

Gaume J, van Herwijnen A, Schweizer J, Chambon G and Birkeland K (2015) Modeling of crack propagation in weak snowpack layers using the discrete element method. Cryosphere, 9, 1915-1932 (doi: 10.5194/tc-9-1915-2015)

Gauthier D and Jamieson B (2008) Evaluation of a prototype field test for fracture and failure propagation propensity in weak snowpack layers. Cold Reg. Sci. Technol., 51(2-3), 87-97 (doi: 10.1016/j. coldregions.2007.04.005)

Heierli J, Gumbsch P and Zaiser M (2008) Anticrack nucleation as triggering mechanism for slab avalanches. Science, 321(5886), 240-243 (doi: 10.1126/science.1153948)

Hutchinson JW and Suo Z (1992) Mixed-mode cracking in layered materials. Adv. Appl. Mech., 29, 63-191 (doi: 10.1016/S00652156(08)70164-9)

Jamieson J and Johnston C (2001) Evaluation of the shear frame test for weak snowpack layers. Ann. Glaciol., 32, 59-69 (doi: 10.3189/172756401781819472)

LeBaron A and Miller D (2014) An energy-based microstructural constitutive model for fracture in snow. Proceedings of the International Snow Science Workshop, Banff, AB, Canada, 134-138

Löwe $\mathrm{H}$ and van Herwijnen A (2012) A poisson shot noise model for micro-penetration of snow. Cold Reg. Sci. Technol., 70, 62-70, ISSN 0165-232X (doi: 10.1016/j.coldregions.2011.09.001)

Marshall H and Johnson J (2009) Accurate inversion of high-resolution snow penetrometer signals for microstructural and 
micromechanical properties. J. Geophys. Res. Solid Earth, 114, F04016 (doi: 10.1029/2009JF001269)

McClung DM (1979) Shear fracture precipitated by strain softening as a mechanism of dry avalanche release. J. Geophys. Res., 84 (B7), 3519-3526 (doi: 10.1029/JB084iB07p03519)

McClung DM (1981) Fracture mechanical models of dry slab avalanche release. J. Geophys. Res., 86(B11), 10783-10790 (doi: 10.1029/JB086iB11p10783)

McClung DM (2007) Fracture energy applicable to dry snow slab avalanche release. Geophys. Res. Lett., 34(2), ISSN 0094-8276 (doi: 10.1029/2006GL028238)

McClung DM (2009) Dry snow slab quasi-brittle fracture initiation and verification from field tests. J. Geophys. Res. Earth, 114, ISSN 0148-0227 (doi: 10.1029/2007JF000913)

McClung DM (2015) Mode ii fracture parameters of dry snow slab avalanche weak layers calculated from the cohesive crack model. Int. J. Fracture, 193(2), 153-169 (doi: 10.1007/s10704-015-0026-1)

Mellor M (1975) A review of basic snow mechanics. IAHS-AISH Pub., 114, 251-291

Narita H (1980) Mechanical behavior and structure of snow under uniaxial tensile stress. J. Glaciol., 26(94), 275-282

Podolskiy E and 8 others (2014) Healing of snow surface-to-surface contacts by isothermal sintering. Cryosphere, 8(5), 1651-1659 (doi: 110.5194/tc-8-1651-2014, 2014)

Reiweger I and Schweizer J (2010) Failure of a layer of buried surface hoar. Geophys. Res. Lett., 37(24), L24501, ISSN 0094-8276 (doi: 10.1029/2010GL045433)

Reiweger I and Schweizer J (2013) Weak layer fracture: facets and depth hoar. Cryosphere, 7(5), 1447-1453, ISSN 1994-0416 (doi: 10.5194/tc-7-1447-2013)

Reiweger I, Gaume J and Schweizer J (2015) A new mixed-mode failure criterion for weak snowpack layers. Geophys. Res. Lett., 42(5), 1427-1432 (doi: 10.1002/2014GL062780.)

Reuter B, Proksch M, Löwe H, van Herwijnen A and Schweizer J (2013) On how to measure snow mechanical properties relevant to slab avalanche release. Proceedings of the International Snow Science Workshop, Grenoble, France, 7-11 October 2013, 7-11

Reuter B, Schweizer J and van Herwijnen A (2015) A process-based approach to estimate point snow instability. Cryosphere, 9, 837847 (doi: 10.5194/tc-9-837-2015, 2015)

Scapozza C (2004) Entwicklung eines dichte- und temperaturabhängigen Stoffgesetzes zur Beschreibung des visko-elastischen Verhaltens von Schnee. (PhD thesis, ETH Zürich)
Schneebeli M and Johnson JB (1998) A constant-speed penetrometer for high-resolution snow stratigraphy. Ann. Glaciol., 26, 107-111

Schweizer J (1998) Laboratory experiments on shear failure of snow. Ann. Glaciol., 26, 97-102

Schweizer J and Camponovo C (2002) The skier's zone of influence in triggering slab avalanches. Ann. Glaciol., 32, 314-320 (doi: 10.3189/172756401781819300)

Schweizer J, van Herwijnen A and Reuter B (2011) Measurements of weak layer fracture energy. Cold Reg. Sci. Tech., 69(2-3), 139144 (doi: 10.1016/j.coldregions.2011.06.004)

Schweizer J, Reuter B, van Herwijnen A, Jamieson J and Gauthier D (2014) On how the tensile strength of the slab affects crack propagation propensity. Proceedings of the 2014 International Snow Science Workshop, Banff, AB, Canada, 164-168

Sigrist C (2006) Measurement of fracture mechanical properties of snow and application to dry snow slab avalanches. (PhD thesis, ETH Zürich, diss). ETH No. 16736

Sigrist C and Schweizer J (2007) Critical energy release rates of weak snowpack layers determined in field experiments. Geophys. Res. Lett., 34, L03502 (doi: 10.1029/2006GL028576)

Szabo D and Schneebeli M (2007) Subsecond sintering of ice. Appl. Phys. Lett., 90(15), 151916

van Herwijnen A and Heierli J (2009) Measurement of crack-face friction in collapsed weak snow layers. Geophys. Res. Lett., 36 (23), L23502, ISSN 0094-8276 (doi: 10.1029/2009GL040389)

van Herwijnen A and Heierli J (2010) A field method for measuring slab stiffness and weak layer fracture energy. Proceedings of the International Snow Science Workshop, Lake Tahoe, CA, USA, 2010, 232-237

van Herwijnen A and Jamieson B (2005) High-speed photography of fractures in weak snowpack layers. Cold Reg. Sci. Technol., 43 (1-2), 71-82 (doi: 10.1016/j.coldregions.2005.05.005)

van Herwijnen A and Miller D (2013) Experimental and numerical investigation of the sintering rate of snow. J. Glaciol., 59(214), 269-274, ISSN 0022-1430 (doi: 10.3189/2013JoG12J094)

van Herwijnen A, Schweizer J and Heierli J (2010) Measurement of the deformation field associated with fracture propagation in weak snowpack layers. J. Geophys. Res. Earth, 115, F03042, ISSN 0148-0227 (doi: 10.1029/2009JF001515)

Zeidler A and Jamieson B (2006) Refinements of empirical models to forecast the shear strength of persistent weak snow layers PART A: layers of faceted crystals. Cold Reg. Sci. Tech., 44(3), 184193 (doi: 10.1016/j.coldregions.2005.11.005) 